\title{
Analysis of Hay Demand from Pastoralism Systems on Viability of Hay Production as a Climate Adaptation Strategy in Kajiado County, Kenya
}

\author{
Judy Kimaru ${ }^{1 *}$, Henry Mutembei ${ }^{2}$, John Kaunga Muthee ${ }^{2}$ \\ ${ }^{1}$ Wangari Maathai Institute for Peace and Environmental Studies, The University of Nairobi, Nairobi, Kenya \\ ${ }^{2}$ College of Agriculture and Veterinary Studies, The University of Nairobi, Nairobi, Kenya \\ Email: ‘judykimaru@gmail.com, hmutembei@uonbi.ac.ke, john.kaunga@gmail.com
}

How to cite this paper: Kimaru, J., Mutembei, H. and Muthee, J.K. (2021) Analysis of Hay Demand from Pastoralism Systems on Viability of Hay Production as a Climate Adaptation Strategy in Kajiado County, Kenya. Agricultural Sciences, 12, 1089-1102.

https://doi.org/10.4236/as.2021.1210070

Received: July 20, 2021

Accepted: October 9, 2021

Published: October 12, 2021

Copyright $\odot 2021$ by author(s) and Scientific Research Publishing Inc. This work is licensed under the Creative Commons Attribution International License (CC BY 4.0).

http://creativecommons.org/licenses/by/4.0/

\begin{abstract}
Hay production is a flagship project under drought risk reduction and climate change adaptation programs in pastoralism livestock systems in Kenya. For decision-makers to plan and evaluate their projects, they need localized data on hay production and supply and to understand what attitudes influence demand for hay by pastoralists. A cost-benefit analysis on 23 hay farms and a questionnaire knowledge, attitude and practice survey on 340 pastoralists in Kajiado Central were undertaken. This study provides the hay production versus hay deficit figures in Kajiado Central County. The study also measures the financial losses livestock keepers incur during drought migration and correlates these losses against livestock keeper's decision to buy hay for their animals. The study established that the drought in 2017, Kajiado Central County had a $48 \%$ hay deficit (2,580,000 hay bales) worth about KES 902 million needed to cover three months of the severest period of the drought. At the same time, hay production and supply were 49,138 grown hay and 3292 purchased hay bales and 6177 bags of commercial feeds and forage. The study also found that $86 \%$ of livestock keepers buy hay only when their animals started dying at the severest period of the drought. Hay buying mainly occurs in drought years, and averagely for three months only. From 2005 to 2020, there have been five years of severe drought. Because hay production is a critical climate change adaptation and mitigation strategy for droughts, Kajiado needs to reduce the hay deficit by $67 \%$ (average of 2015 \& 2017), disaster management planners need to align the hay supply to hay purchasing practices. In addition, decision-makers need to address the low hay supply by tackling the challenges of hay production. Furthermore, disas-
\end{abstract}


ter management planners could use the study to determine the trigger points

to start disaster response for livestock feed.

\section{Keywords}

Hay Production, Drought Risk Reduction, Disaster Resilience, Climate Change Adaptation, Pastoralism

\section{Introduction}

Livestock production provides around 90 percent of employment and family income in the arid and semi-arid lands (ASALs), where vulnerability to drought is acute. The increased incidence of droughts across the ASALs gives communities less time to recover and rebuild assets and resilience. Migrating livestock herds to different dry and wet season grazing zones is the predominant drought mitigation strategy practiced by pastoralists. Over the years, options to migrate livestock have been shrinking due to climate change and land use changes leading to the need for alternative livestock feeding options. The limited feeding options are evident when one looks at the livestock losses from drought within the most recent decade alone, which are estimated at more than US $\$ 1.08$ billion [1].

Studies show that smallholder farmers' exposure to and awareness of different fodder crops in Kenya is high. However, despite this high awareness, only 55\% grow at least one fodder type on their farms. Furthermore, frequent droughts due to climate change and poor agricultural land-use practices have significantly contributed to degradations and loss of natural pastures, especially in the ASAL area [2].

A 2018 study suggested that Kenya suffers large deficits of livestock feeds, mainly forage for dairy cattle. The deficit is over 3.6 billion bales of hay annually, worth USD nine billion. Moreover, the demand is expected to increase, given the emerging fodder demand by neighbouring counties. Production of these quantities of fodder would require additional 15 million acres of land under fodder crops and pasture which could be achieved by shifting to the utilization of the arid and semi-arid areas [3].

Fodder production has also been adopted in Kenya as a strategy to mitigate the adverse effects of unsustainable grazing practices and rehabilitate degraded lands. Empirical evidence shows that the rehabilitation of rangelands using enclosures had a significant impact on reducing soil erosion and improving water infiltration and internal drainage. Communities around the Lake Baringo basin have benefited from the sale of grass seeds and hay from enclosures established to restore indigenous vegetation. Range rehabilitation through enclosures in West Pokot County has benefited pastoralists through the sale of grass and grass seeds and access to dry season grazing, leading to improved livestock productivity. Like other communities living in the drylands, agro-pastoralists in Makueni 
County have embraced fodder production to increase their livestock productivity, ensuring feed availability in the dry periods and selling hay and grass seeds for income. Past studies have also reported significant contributions of fodder production to households' income. Out of 10 tons of indigenous perennial grass seed planted annually in Baringo, pastoral groups have earned an annual income of up to KSh1.5 million. Other benefits obtained by these households include increased and diversified livelihoods sources arising from improved livestock productivity and sale of hay and grass seed, and rehabilitation of degraded lands through pasture establishments and enclosures [4]. However, fodder production in the drylands of Kenya has also been reported to face several constraints, among them high costs of land preparation and grass seed, weed problems, poor seed quality, high input costs, lack of seed harvesting skills, and lack of working capital [2].

Inadequate quality and quantity of animal feed and the growing demand for fodder motivated government initiatives to support fodder establishment, production, and marketing. One such initiative was introducing several natural fodder improvement technologies in the drylands to increase feed availability during the dry periods and diversify income through the sale of hay and grass seed among communities living in the ASALs. These initiatives, coupled with a demand for fodder and the inability of many farmers to establish and preserve enough fodder on-farm, created the emergence of a commercial fodder sector in Kenya [3].

This research looks at the demand for hay and grazing resources from pastoralists and their purchasing practices during drought years versus hay production in Kajiado Central County. This information will provide decision-makers and planners with actual planning figures for drought response and filling the hay deficit through hay production that is cognizant of the pastoralist buying practices to encourage resilience in pastoral livestock systems in the county.

\section{Purpose}

The study objectives were to:

1) Establish the hay deficit during drought years in Kajiado Central County.

2) Analyze the monetary costs and losses incurred by pastoralists due to livestock migration in Kajiado Central County.

3) Provide decision-makers with planning data for livestock animal feed (hay) needs for disaster response and drought resilience building under the climate-smart drought risk reduction strategy of Kajiado County.

\section{Materials and Methods}

Kajiado County is about $21,900 \mathrm{~km}^{2}$ and has five sub-counties with a population of $1,117,840$, and the study was limited to two sub-counties in Kajiado Central with a population of 372,335 [5] and 584,643 livestock (95,534 cattle, 218,961 sheep, and 270,148 goats) [6] (Figure 1). 


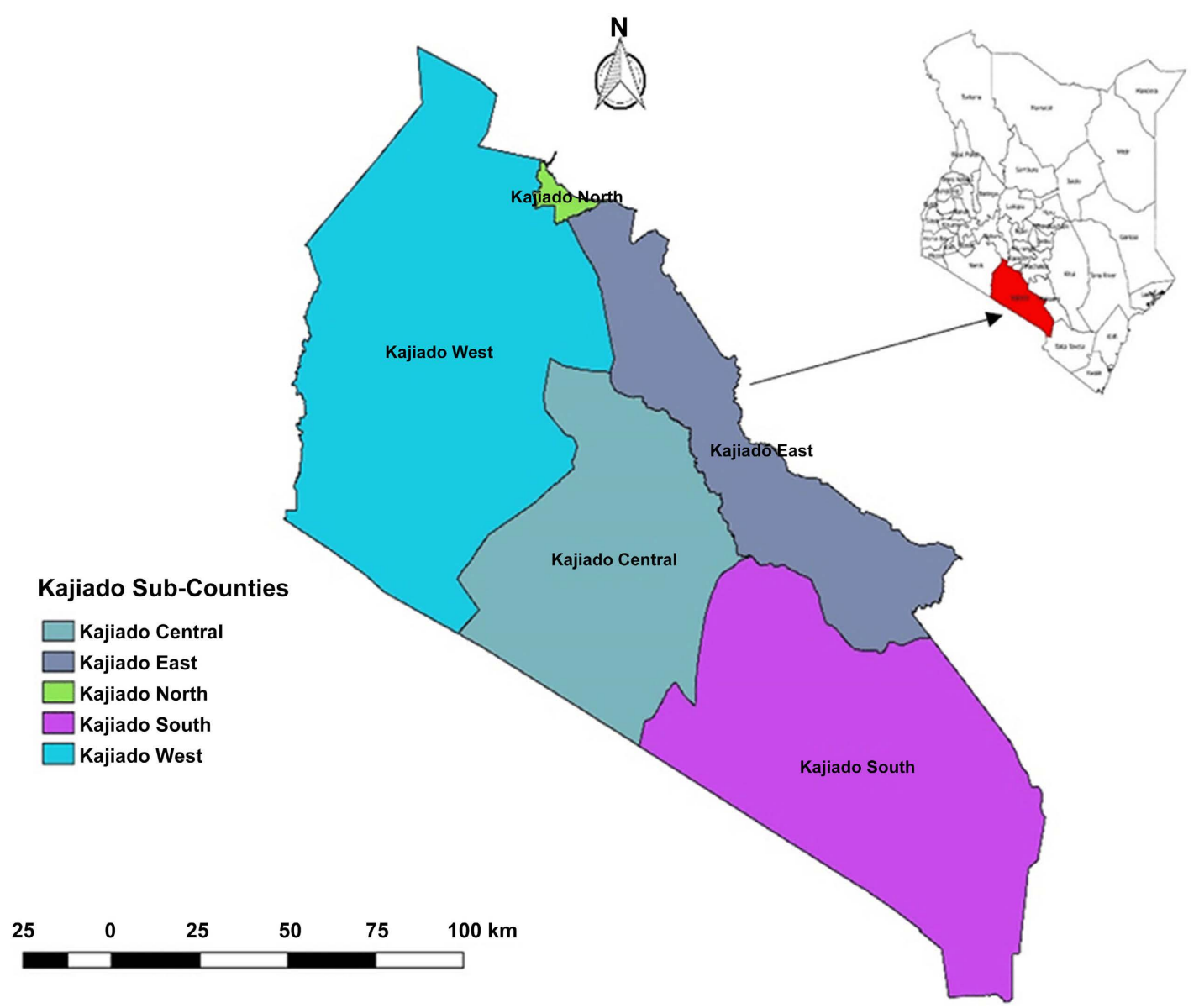

Figure 1. Map of Kajiado central county.

\subsection{Knowledge, Attitude and Practice (KAP) Survey}

This study applied a cross-sectional non-experimental research design collecting data from 2005 to 2020 . The study used a mixed-method approach of field survey and desktop literature review. Stratified random sampling was used to select 354 livestock farmers interviewed using a structured knowledge, attitude and practice (KAP) survey questionnaire and semi-structured questions for the key informant interviews. Secondary data from published and unpublished records were used to complement the primary data. The study sampled respondents from Central Kajiado and Isinya sub-counties, including the municipalities of Kajiado town, Ngagateak, Namanga. The questionnaire was pre-tested in the field and modified accordingly. From the selected sub-counties, every fourth livestock farmer was selected until the 354 livestock farmers were selected.

\subsection{Determining Drought versus Normal Years}

The survey asked the respondents to recall the worst drought years and compare them to normal years. Considering the long recall period that respondents were asked to compare normal and drought seasons of the past, the study triangulated their information with data from the National Drought Management Authority 
(NDMA), 2009 Kenya National Bureau of Statistics for livestock, and 2019 National housing and population census. This triangulation helped to compare animal migration patterns, livestock losses due to migration, changes in livestock prices and productivity caused by drought, water availability, animal health, livestock death, sicknesses and associated causes.

\subsection{Determining Yearly Migration Costs}

Yearly migration cost estimates were arrived at by establishing the median values (median minimizes the errors brought about by inliers and outliers) of monthly costs incurred by herders during a dry season. These monthly migration costs were limited to permanent herders cost, temporary herders cost, security cost, movement permits, grazing permits, rent for grazing land, water for animals, commercial feeds, veterinary fees, and other fees and confiscation fines. After estimating the monthly costs of migration for dry seasons, the number of dry seasons in each year was obtained from NDMA databases, upon which the yearly cost of migration was calculated. Similarly, Monthly migration costs were estimated for the normal years using the same procedure. The number of migration months was taken to be three [3] for normal years and three months of the severest period of a drought year to enable the yearly costs of migration estimates to be compared between a normal and drought year.

\subsection{Econometric Model to Determine the Relationship between Livestock Losses and the Number of Bales of Hay Bought}

The relationship between livestock losses and the quantity of hay that farmers/pastoralists bought during drought seasons in Kajiado central was determined using the below econometric model:

$$
L=f(H b)
$$

After constructing the model, we defined the equation and determined the sign of the independent variable, which was identified through research, theory and logical assumptions. Then, a linear regression using the ordinary least square (OLS) regression technique was run to determine how the magnitude of livestock losses during drought seasons influences pastoralists to buy hay in Kajiado county. Microsoft Office 2016 (excel) data analysis ToolPak was used for the analysis. The test was done at a $95 \%$ confidence level, with a p-value, alpha $=$ 0.05 .

The regression model for analysis is therefore as follows:

$$
\begin{gathered}
L=\beta_{0}+\beta_{1} H b+\varepsilon \\
L=f(H b)
\end{gathered}
$$

where:

$L$ : Livestock losses during drought years in Kenya shillings (KES);

$H b$ : Bales of hay bought by farmers (15 kg bale);

$\beta_{1}$ : Regression beta coefficient that the model estimates in the study indicate 
the effect of a unit change in the independent variable on the dependent variable; $\varepsilon$. Stochastic term/error term.

\section{Results}

The study looked at the correlation between drought years and normal rainfall years with the monetary loss's pastoralists incurred whilst migrating their animal's long distances in search of grazing grass and water. It is important to note that pastoralists migrate their animals annually, with the distances travelled determined by availability of water and grass. In drought years, these distances increase substantially.

The survey established that the worst drought years over the past 15 years were 2005, 2007, 2009, 2015, and 2017. Over the same period, 2008, 2012, 2018, 2019, and 2020 were normal years with good rains and short dry spells that did not cause drought-related livestock losses or depletion of pasture for grazing. The monthly costs incurred during the three months of migration included salaries of permanent and temporary herders, security guards for herds, livestock movement permits, grazing permits, rent for grazing land from private landowners, water for animals, commercial feeds, veterinary fees, and confiscation fines law enforcement, and other miscellaneous fees.

\subsection{Livestock Financial Losses Due to Drought Migration}

The monetary value of livestock losses due to drought-related causes, namely, starvation, wildlife predation, sickness, and distress selling, increased eleven-fold from the drought of 2005 compared to the drought of 2017, as shown in Figure 2. Migration costs increased by $416 \%$ in drought years compared to normal years. Labour and grazing costs accounted for $74 \%$ of all migration costs, as shown in Figure 3.

\section{Estimate of livestock losses due to drought in Kajiado County}

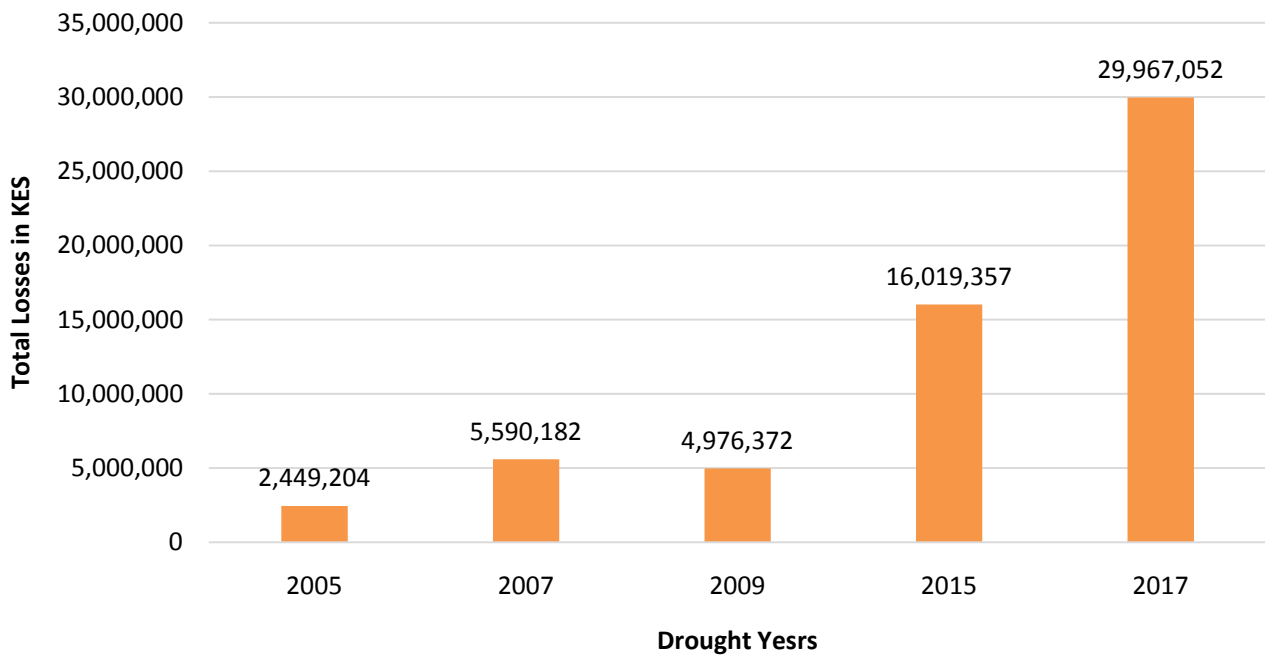

Figure 2. Livestock losses in KES due to drought. 


\section{Comparative cummulative costs in normal vs drought years from 2005 to 2020}

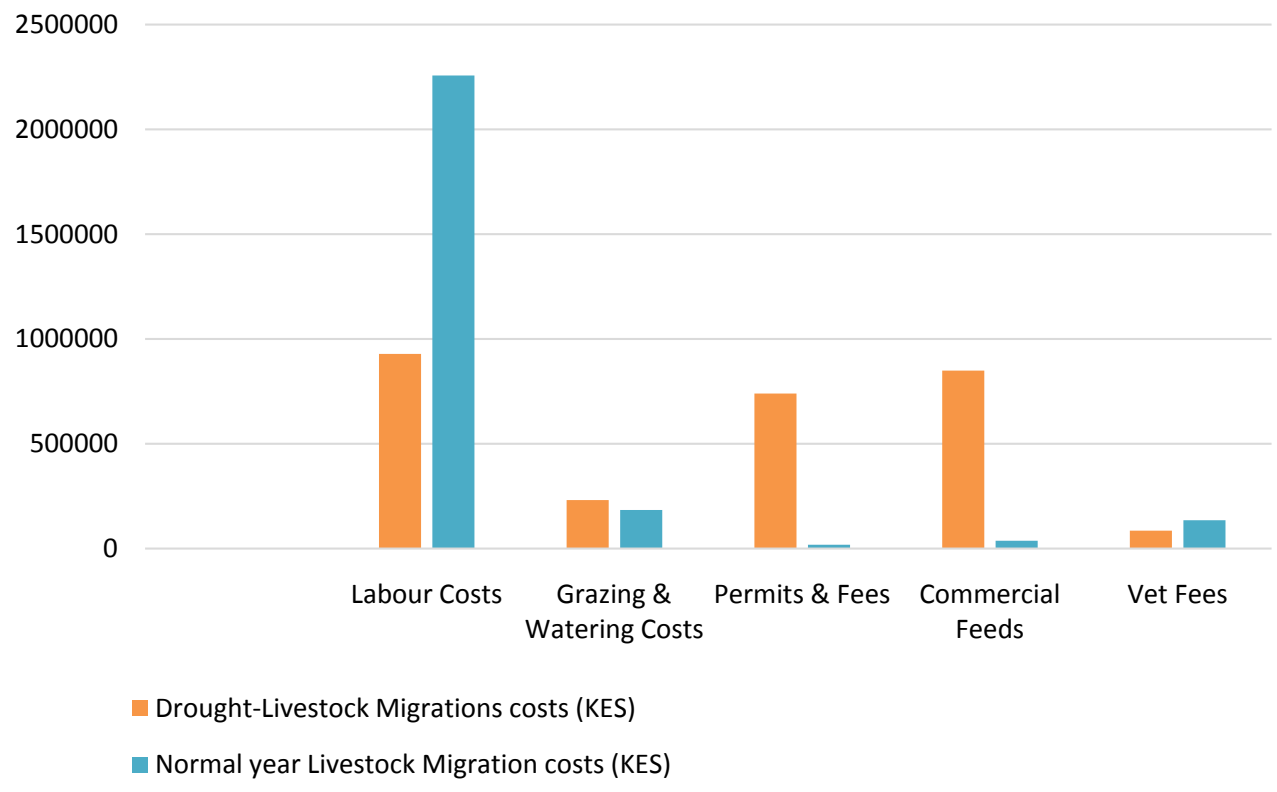

Figure 3. Comparative cumulative costs of drought versus normal years from 2005 to 2020.

\subsection{Causes of Financial Livestock Losses during Drought Migration}

Death by starvation accounts for $35 \%$ and $42 \%$ of monetary losses in cattle and shoats, respectively. Distress selling was the second-highest, accounting for 35\% to $46 \%$ of cattle and shoats' monetary losses. Finally, wildlife predation accounts for $6 \%-7 \%$ of losses as the study area is within the Amboseli National Park ecosystem (Figure $4 \&$ Figure 5).

\subsection{Correlation between Feeding Options and Livestock Migration Losses from 2005 to 2017}

The 2017 drought recorded the highest financial at approximately KES 30M. As shown in Figure 6, hay purchasing increased from 13\% in 2005 to 37\% in 2017, while own-grown hay increased drastically from a low of $2 \%$ in 2005 to $21 \%$ in 2017. Other forages as a feeding option averaged $28 \%$ from 2005 to 2017 . The option of purchasing commercial feeds has dropped over the past 15 years. For instance, in 2005 , commercial feeds accounted for $60 \%$ of the feeds used, dropping to $35 \%$ in 2017.

Most farmers preferred buying hay rather than growing their hay in both normal and drought years. Moreover, farmers preferred feeding their livestock with hay over commercial feeds during droughts. From 2015 to 2017, the preference for feeding using purchased hay increased from $14 \%$ to $37 \%$, respectively, compared to the $21 \%$ preference increase of feeding using own-grown hay. These low percentages show that farmers are still not growing enough hay for their own needs. This finding is similar to another study conducted in ASAL 
\% Cost of drought migration losses in Cattle (2005-2017)

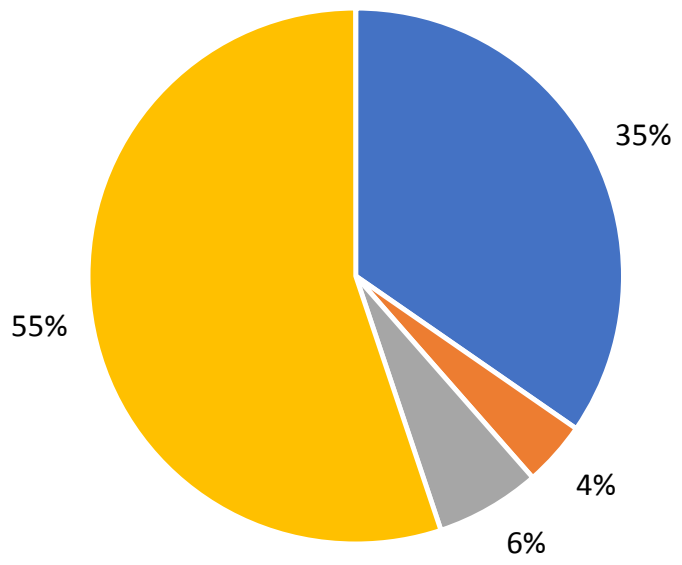

- Death $\quad$ Sick Animals $\quad$ Killed by wildlife $\backsim$ Sold to avoid loss from drought

Figure 4. Cattle losses in KES due to drought.

\% Cost of drought migration losses in Sheep \& Goats (2005-2017)

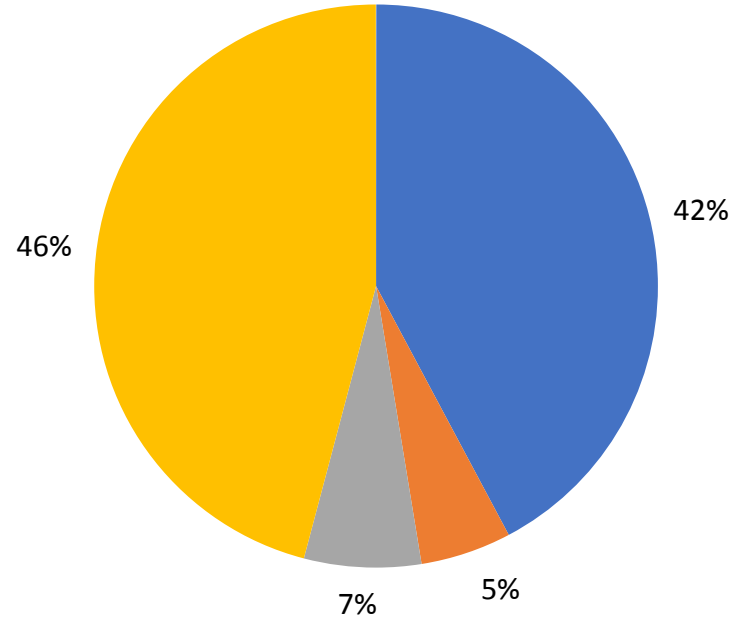

Death $\quad$ Sick Animals $\square$ Killed by wildlife $\square$ Sold to avoid loss from drought

Figure 5. Percentage sheep and goats losses due to drought.

county, Tharaka Nithi (an ASAL county), where only $1 \%$ of the farmers grew forage on less than three acres of their land [7] (Figure 7).

Regression analysis indicates a strong positive coefficient of correlation $\mathrm{R}=$ 0.93 between the livestock losses that pastoralists incur during droughts and their tendency to buy hay to sustain their animals. This correlation is particularly true if we refer to Figure 12, where the estimated livestock losses rose from $16,019,357$ in 2015 to $29,967,052$ in 2017. Consequently, farmers also increased the purchase of bales of hay up to 18,174 bales (Figure 11). Another crucial correlation indicator is the $\mathrm{R}$ square value $(0.8617)$ which shows that $86 \%$ of pastoralists 


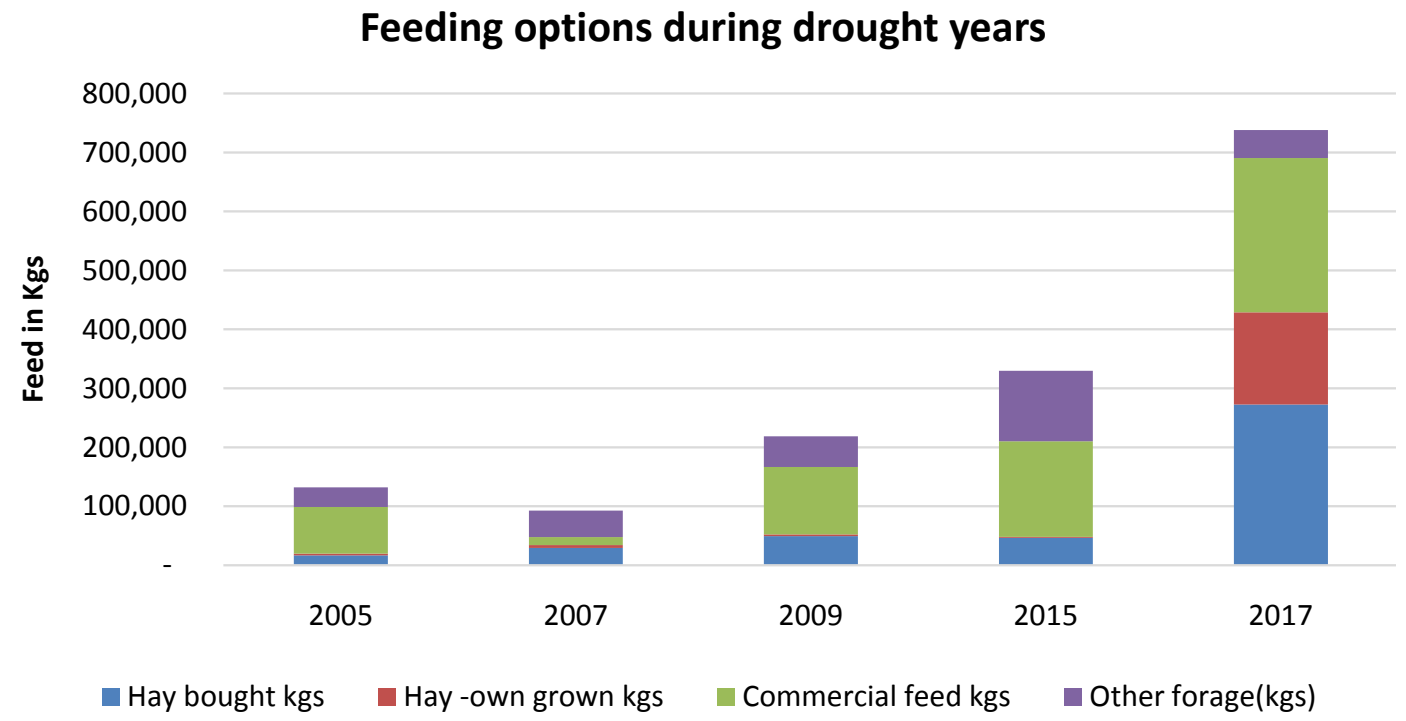

Figure 6. Livestock feeding options during droughts.

\begin{tabular}{|l|l|}
\hline \multicolumn{2}{|l|}{ Regression Statistics } \\
\hline Multiple R & 0.9283 \\
\hline R Square & 0.8617 \\
\hline Adjusted R Square & 0.8444 \\
\hline Standard Error & 3813156.5190 \\
\hline Observations & 10.0000 \\
\hline
\end{tabular}

\begin{tabular}{|l|l|l|l|l|}
\hline & Coefficients & Standard Error & t Stat & $P$-value \\
\hline Intercept & 1418410.8873 & 1380476.7202 & 1.0275 & 0.3343 \\
\hline & & & & \\
Hay bought (bales) & 1628.8208 & 230.7116 & 7.0600 & 0.0001 \\
\hline
\end{tabular}

Figure 7. Correlation between feeding and livestock losses.

decision to buy hay was triggered by the losses they incurred from the drought. However, this is only significant at a $\mathrm{p}$-value $(\mathrm{p}<0.005), \mathrm{n}=10$. The remaining reasons farmers bought much hay can be explained by other factors not captured in this model.

The line of best fit graph (Figure 8) is a good predictor of livestock losses in KES versus hay bales purchased, a drastic increase in the purchase of hay is an indicator of high livestock losses. Therefore, monitoring the hay market sales can be used as an indicator of the severity of the drought has peaked and therefore trigger a decision to commence disaster response-feeding interventions.

\subsection{Hay Production in Kajiado Central County}

From 2015, hay production has increased by over $60 \%$ peaking in 2018 . The drop in hay production in 2019 is because some large farms opted not to harvest their hay grass leaving it to grow on the farm as there is no demand for hay in good/normal rain years as free grazing resources are available to pastoralists (Figure 9). 


\section{Line of best fit}

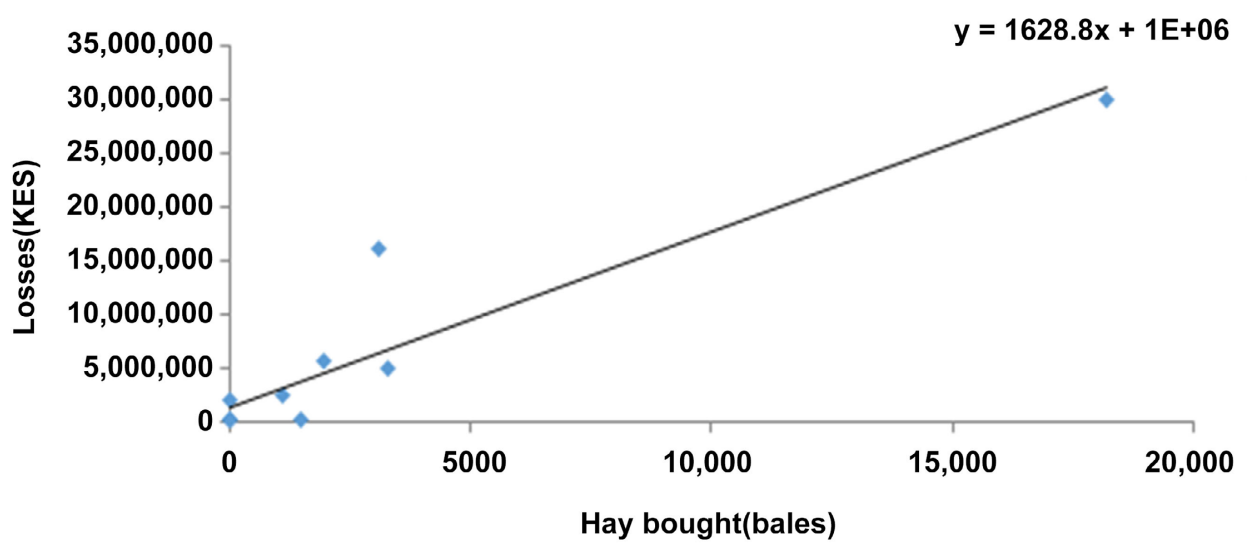

Losses(KES)

Figure 8. Predicator of the severity of drought.

\section{Annual hay production (bales) harvested}

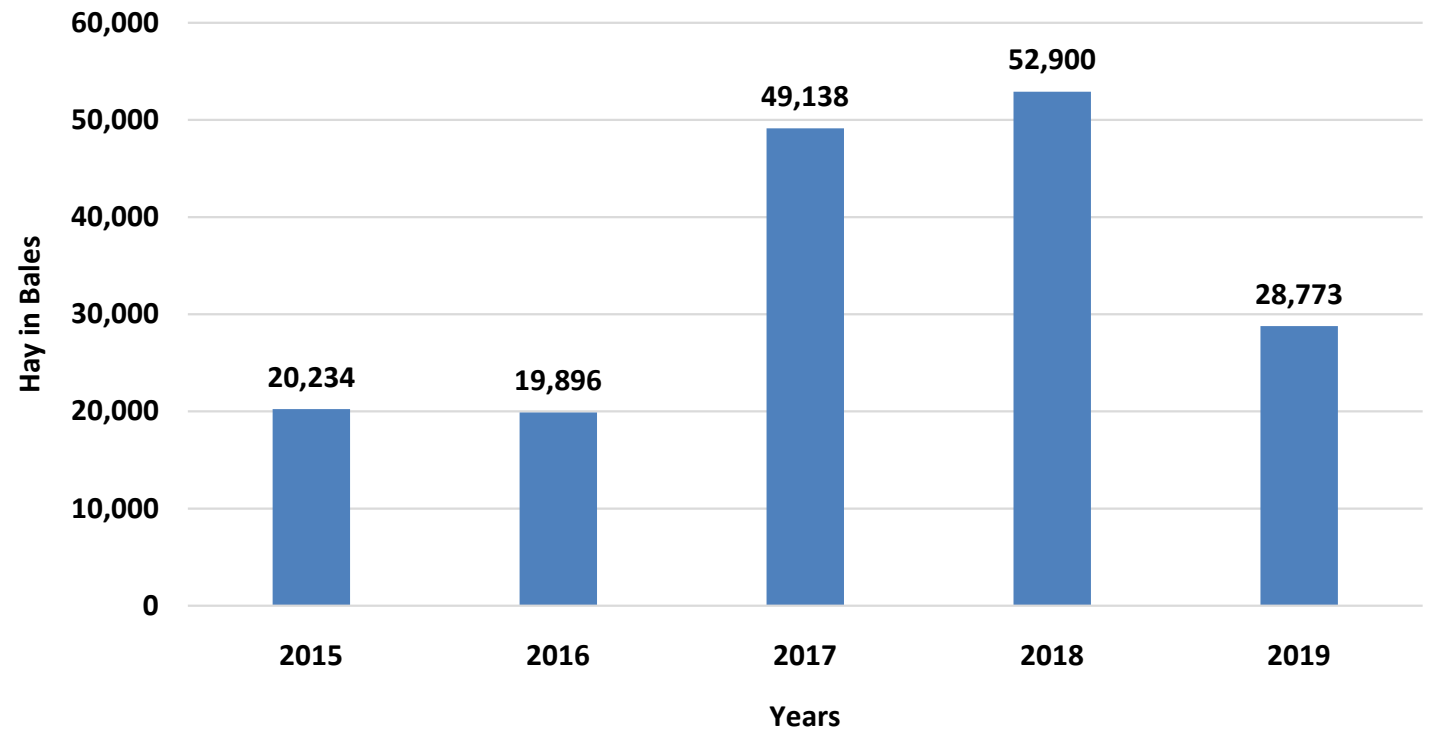

Figure 9. Hay production from 2015-2019.

\subsection{Hay Deficit in Kajiado Central County}

In the droughts of 2005, 2007 and 2009, there was over 95\% hay deficit in the hay. This situation improved in the 2015 and 2017 droughts. In $2017(49,138)$, bales of hay were harvested accounted for $24 \%$ of the total amount of bales needed to sustain livestock during the 3-month drought spell that year (Figure $10)$.

Figure 11 illustrates the hay demand, that is, the number of bales needed for a three-month dry season. The hay deficit in 2015 was $86 \%$ while in 2017 the hay deficit was $48 \%$, which gives an average hay deficit of $67 \%$ for the recent droughts of 2015 and 2015, providing an indication of the expected hay deficit in the next drought after 2020. 


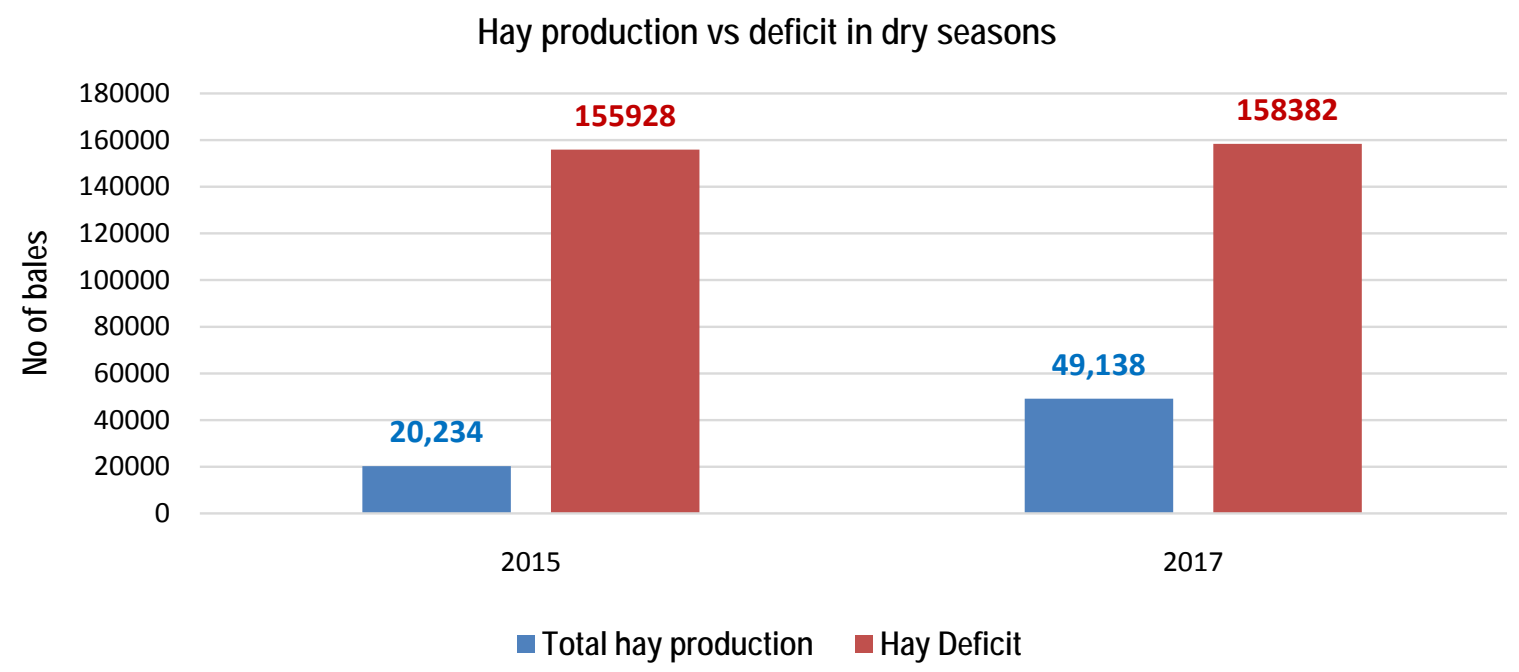

Figure 10. Number of hay bales bought versus hay deficit.

\section{Hay production, Hay purchasede versus deficit}

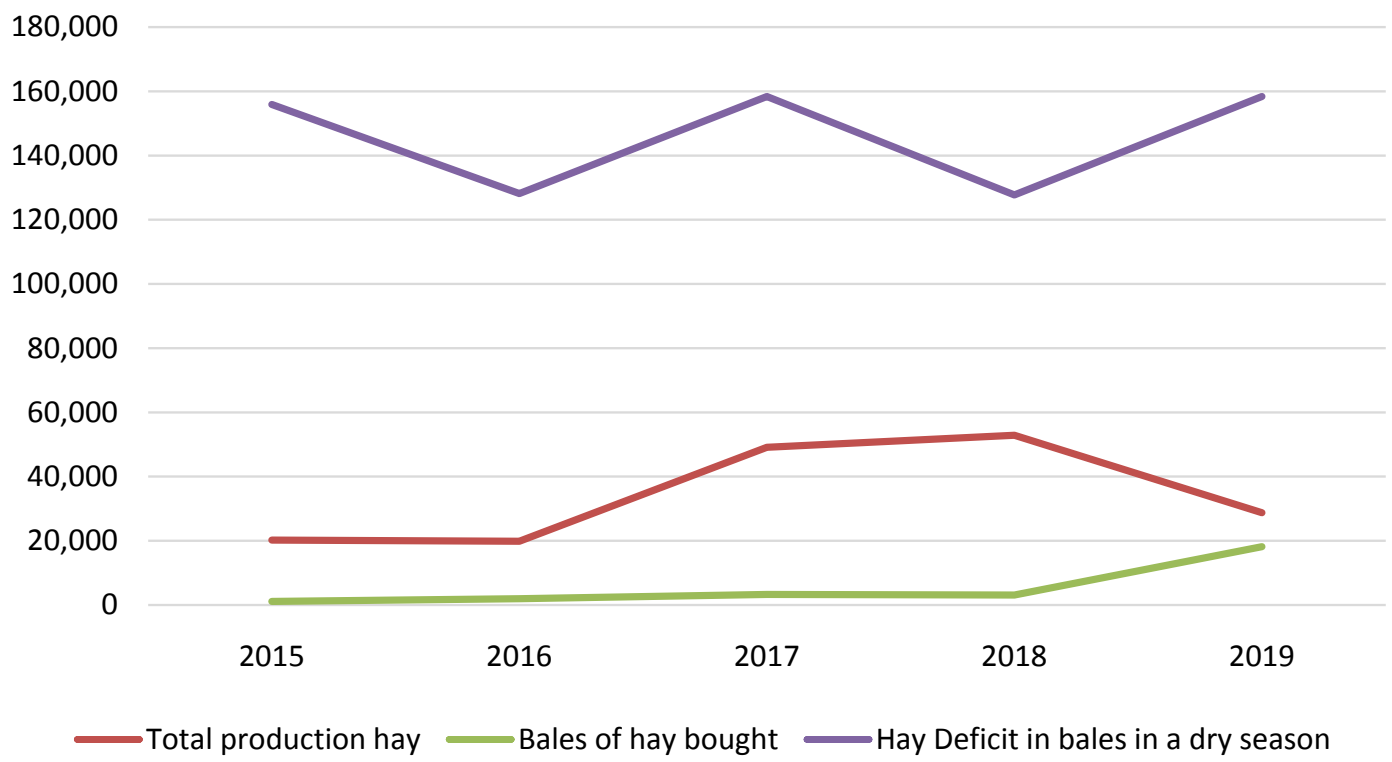

Figure 11. Hay production versus hay purchased against hay deficit.

\subsection{Livestock Losses in Drought Seasons Kenyan Shillings (KES) versus Hay Deficit}

Figure 12 illustrated the monetary impact of livestock losses caused by the hay deficit.

Despite increasing, livestock losses caused by droughts, the number of bales of hay needed to sustain the animals during the droughts did not change much, as illustrated in Figure 12, in 2005 and 2017, where hay bales deficit was valued at KES 54.5M and 55.4M respectively, while at the same time the livestock losses rose from KES 2.5M in 2005 to KES $30 \mathrm{M}$ in 2017. Moreover, about 5256 and 5866 cattle migrated in 2005 and 2017, respectively. 


\section{A comparison between total livestock losses due to migration and hay deficit (KES) in drought seasons}

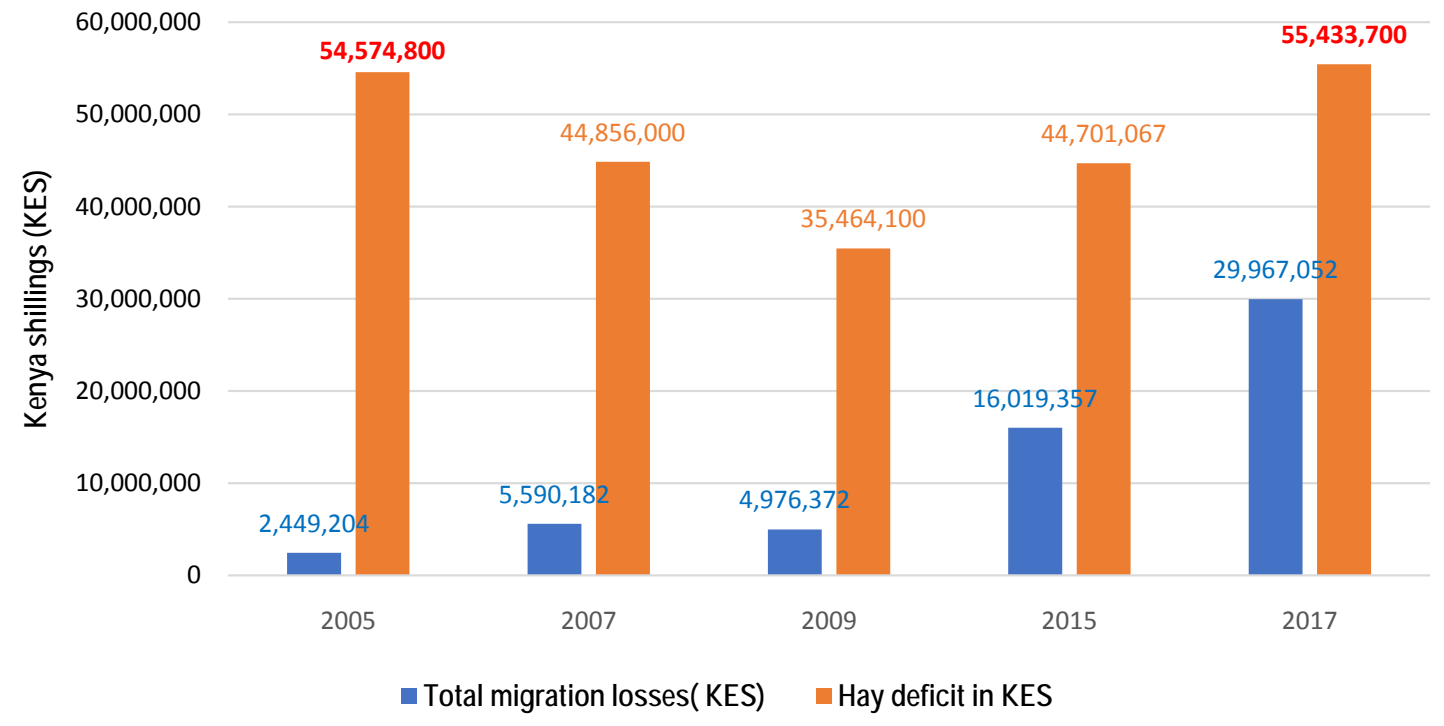

Figure 12. A comparison between total livestock losses and hay deficits in a 3-month dry season.

Extrapolating from the livestock figures from the national census 2009, the Kajiado Central County has an estimated deficit of 2,580,000 bales of hay worth about KES 902 million needed to cover three months in an average drought year.

\section{Discussion}

Hay is a vital drought risk reduction strategy that can reduce the pressure on grazing lands that traditional livestock migration practices exert. However, the quantity of hay available from both own-grown and purchased sources is still low, resulting in an average of $67 \%$ hay deficit projection-the hay deficit in 2015 was $87 \%$, improving in 2017 to a deficit of $48 \%$ due to increased hay production. This high hay deficit means that the available hay is insufficient to replace or substantially reduce the large herds that migrate during droughts. The inadequate hay production also means that the livestock sector cannot reach the resilience levels required to mitigate against the high livestock losses during droughts. The low resilience of the livestock system is illustrated by an increase of $1124 \%$ from 2005 to 2020 in livestock losses incurred due to death, sickness, wildlife predation, and distress sales.

The feeding options employed by pastoralists further demonstrate that hay accounts for below $60 \%$ of the available feed available. For instance, in 2017, the feeding options used were: commercial feeds accounted for 35\%, other forages account for $7 \%$, own grown hay $21 \%$, and purchased hay $37 \%$. Nevertheless, there is a strong demand for hay, as illustrated in the $93 \%$ correlation between demand for hay and drought-related livestock losses.

The demand for hay is still huge and currently unmet in Kajiado, a finding that is in line with the 2017 study that found that Kenya had a 3.6 billion hay 
deficit [3]. The study also highlights that hay demand is highest for only three months of the severe drought years. From a supply point of view, namely for hay production, meeting a market hay demand whose pattern is five years for every 15 years, and within those five years, the demand is only for three months of the severest drought, which means that hay production at a commercial scale is unattractive for the private sector. The study found that the hay deficit remained around 67\% for the last two drought years of 2015 and 2017. Although an improvement from the previous droughts of 2009 , the private sector still has a relatively low uptake of hay growing for commercial purposes.

Supplying hay to livestock is a significant activity during drought while encouraging pastoralists to grow hay for their use and also commercially is a critical pillar in climate adaptation programs. Against the importance of encouraging hay growing, it is the peculiar behavior of pastoralists who only buy hay during severe drought periods and only in the height of the drought-a period of about three months. Migration and free grazing of livestock is still the dominant practice. For drought risk reduction planners, this is a significant correlation. On the one hand, growing hay is being encouraged against a backdrop of low demand during normal and most drought years; however, on the other hand, is a very high demand for three months during severe droughts. So planners need to incentivize large commercial hay growers while encouraging pastoralists to grow their hay for their use.

\section{Recommendations}

This study shows that there is still a very high hay deficit of approximately $67 \%$ in Kajiado County, and hay production is still below desired levels of standing at $20 \%-26 \%$ of requirements. Decision-makers need to take the result of this study and other studies around hay production to address the challenges that hay producers face that are limiting hay production. By supporting hay producers, the County will be directly supporting the livestock keepers during droughts. The private hay producers need to be supported in ASAL to increase their production and meet the demand for hay in the drought years. The positive impact of having hay available during severe droughts in reducing livestock migration and the resource-based conflicts is well documented. However, the low demand for hay in normal years means hay producers are forced to hold their stock in storage for long awaiting a severe drought, leading to substantial economic losses on their part. As a resilience strategy, the hay production enterprise is still in its infancy stage and needs much support. The organic demand from pastoralists for hay, albeit only during the peak of drought years, means that there is an opportunity to match demand and supply to create a viable hay enterprise.

\section{Acknowledgements}

I wish to thank the people of Kajiado County and all the farmers for their patience and support throughout this research. I also wish to appreciate the Kenya 
Climate Smart Agriculture Project (KCSAP) for funding the research and providing guidance and support.

\section{Conflicts of Interest}

We wish to confirm that there are no known conflicts of interest associated with this publication, and there has been no significant financial support for this work that could have influenced its outcome.

\section{References}

[1] World Bank (2015) Kenya Agriculture Sector Risk Assessment.

[2] Omollo, E.O. (2017) Analysis of Fodder Production and Marketing in the Rangelands of Southern Kenya. B.Sc. Thesis, University of Nairobi, Nairobi.

[3] Auma, J., Rao, J., Githinji, J., Lukuyu, B., Omondi, I. and Baltenweck, I. (2019) USAID-KCDMS Feed and Fodder Value Chain Assessment Report-2018.

[4] Okomboli, L.K. (2015) Fodder Production as an Adaptation Strategy in the Drylands: A Case Study of Producer Groups in Baringo County, Kenya. Thesis, University of Nairobi, Nairobi.

[5] Kenya Bureau of Statistics (2019) 2019 Kenya Population and Housing Census Volume I: Population by County and Sub-County.

[6] Kenya Bureau of Statistics (2009) Livestock Numbers by County.

[7] Nderi, O. (2016) Current Status of Fodder Production, Conservation and Marketing in the Arid and Semi-Arid Lands of Tharaka Nithi County, Kenya. African Journal of Agricultural Research, 11, 2337-2347. https://doi.org/10.5897/AJAR2016.11162 